\title{
AN IODABENZENE STORY
}

Abdel Monem Rawashdeh, ", † Priyakumari C. P., \# Tao Zeng, " and Roald Hoffmann", \#

†Dept. of Chemistry, Yarmouk University, Irbid, 211-63, Jordan

\#Dept. of Chemistry and Chemical Biology, Cornell University, Ithaca, NY 4850 USA 'Dept. of Chemistry, Carleton Univ., Ottawa, Ont. K1S5B6, Canada

ABSTRACT: We call iodabenzene a cyclic $(\mathrm{CH})_{5} \mathrm{I}$ molecule. A planar iodabenzene would have $8 \pi$ electrons, a situation best avoided by an out-of-plane distortion to a birdlike geometry. The electronic structure and charge distribution of this molecule resemble those of Meisenheimer complexes, derivatives of $(\mathrm{CH})_{5} \mathrm{CH}_{2}-$. A similar substitution strategy, of $\pi$-acceptors in ortho and para positions, works in both cases to planarize and stabilize such derivatives. Some $40 \mathrm{kcal} / \mathrm{mol}(73 \mathrm{kcal} / \mathrm{mol}$ for the unsubstituted case) below the bird, a classical 5-iodocyclopentadiene structure awaits, reached through a bicyclic transition state. The calculated activation barrier for the highly exothermic reaction to a classical Lewis structure nevertheless make us optimistic about the chances of detecting, even isolating the bird isomer. 


\section{INTRODUCTION}

Prompted by a question from Gerald F. Koser at Univ. of Akron, we began to think about iodabenzene, represented by the structure 1. As drawn, this structure is not meant to carry any implication about the bonding in the molecule; it only indicates atom connectivity. Note, however, that this molecule, were it to be planar, would have two more electrons than a hypothetical $\left.(\mathrm{CH})_{5}\right|^{2+}$ ring, which would be iso-valence electronic with the well-known pyrylium ion $(\mathrm{CH})_{5} \mathrm{O}^{+}$and pyridine, $(\mathrm{CH})_{5} \mathrm{~N}$. Those two electrons in excess of an aromatic sextet are likely to enter a ring $\pi$-antibonding orbital, not a good thing. Writing a hypervalent structure ${ }^{1,2,3}(2)$ seems like a way out, but detailed consideration of the placement of electrons in such a molecule leads one back to an $8 \pi$ system.

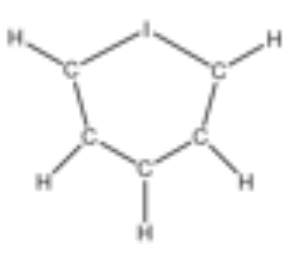

1

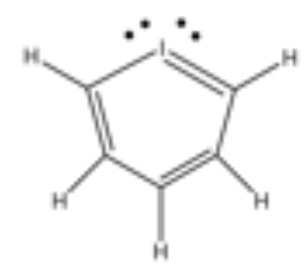

2

lodabenzene and other "halogenabenzenes" were in fact, introduced in the literature by Glukhovtsev. ${ }^{4}$ He thought of two possibilities for halogenabenzene: If the two excess electrons provided by the halogen were to occupy a m level, we would have as mentioned, an $8 \pi$ electron antiaromatic system. On the other hand, if they were to occupy a C-I-C antibonding $\sigma$-orbital, we might have a $6 \pi$-electron aromatic species. Glukhovtsev found that the former situation is preferred to the latter, and that the structure of the $8 \pi$ electron system is planar, based on AM1 and MNDO 
calculations. In this paper, we revisit the seemingly simple iodabenzene structure. It leads us to an informative exploration of alternative $\mathrm{C}_{5} \mathrm{H}_{5}$ l structural possibilities.

\section{RESULTS AND DISCUSSION}

The calculations we report are both wave-function based and DFT ones, at the B3LYP, M06-2X and MP2 levels, ${ }^{5-6}$ with details given in the Supplementary Information (SI) to this paper. We used Def2-TZVPP basis set for all calculations. ${ }^{7}$ We also applied multireference calculations to accurately calculate the singlet-triplet gap. ${ }^{8,9}$ Unless otherwise stated, the calculational results shown are M06-2X type, which gives good main group thermochemistry and kinetics. ${ }^{10}$ The bond lengths are in $\AA$, and energies are in $\mathrm{kcal} / \mathrm{mol}$, throughout the paper. The relative energy values include zero point corrections. The free energy values include thermal corrections corresponding to $298.15 \mathrm{~K}$.

A $\mathrm{C}_{2 v}$-constrained optimization of $\mathbf{1}$ led to $\mathbf{3}$. However, planar $\mathbf{3}$ was characterized by one imaginary frequency in its Hessian matrix; following that mode led to a non-planar, graceful bird-like structure shown in 4 , which is $6 \mathrm{kcal} / \mathrm{mol}$ lower in energy. We shall use this colloquial descriptor, bird, from this point on. The charges resulting from a natural population analysis ${ }^{11}$ (there is some dependence on the method used) are shown in $\mathbf{5}$. These are consistent with an iodonium ion bridging a pentadienyl anion, valence structure 6 . Note especially the accumulation of negative charge ortho and para to iodine. lodonium salts are, of course, common polyvalent iodine compounds. ${ }^{12}$ The planar system has eight $\pi$-type electrons; the non-planarity 
of the bird form is an attempt to escape from this situation, as we will see in a detailed orbital picture further on in this work.

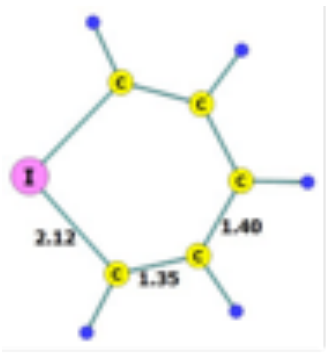

3

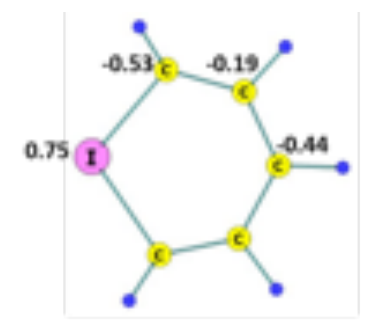

5

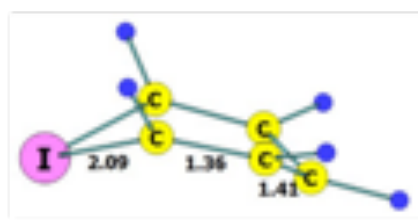

4

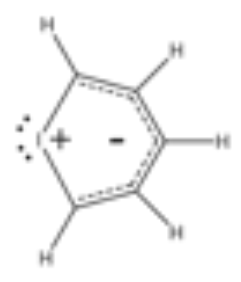

6

We note at this point that Glukhovtsev in his previous work also came up with the preferred zwitterionic valence structure for iodabenzene. Also, as we would infer from the charge distribution of $\mathbf{5}$ or $\mathbf{6}$, the zwitterionic structure would be less likely as the electronegativity of the halogen increases. In fact, we found local minima for bird structures of $(\mathrm{CH})_{5} \mathrm{X}, \mathrm{X}=\mathrm{Br}, \mathrm{Cl}$, but no local minimum of this geometry for $\mathrm{X}=\mathrm{F}$, at B3LYP and MP2 levels. Fluorabenzene is a shallow minimum at M06-2X level.

A Bicyclic Alternative. A structure related to 4 is the bicyclic one (7), which turns out to be not a local minimum, but a transition state. The charge distribution in $\mathbf{7}$ is shown in 8. At first sight, one might think that with a fully formed CC bond, 7 might be described by valence structure 9 , the result of a formally an allowed disrotatory 
six-electron electrocyclic reaction. ${ }^{13}$ However the positive charge on the I is much smaller than in the bird, and the C-I bonds in 7 are also very long. The charge distribution (8) also is not consistent with Lewis structure 9. It is better to think of the bicyclic structure as a transition state for an allowed 1,5-(=1,2-) sigmatropic shift on a 5 -iodocyclopentadiene; we will return to this perspective.

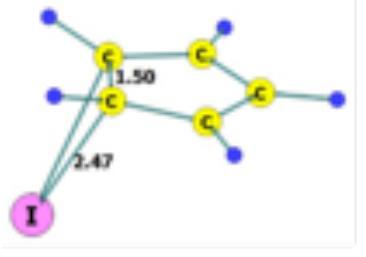

7

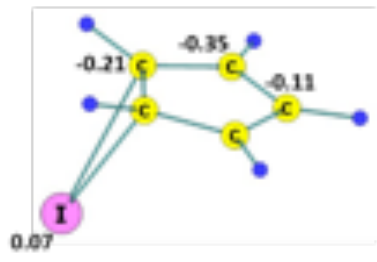

8

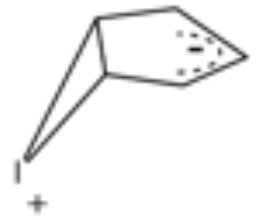

9

And Classical Structures. The bicyclic structure 7, though $55 \mathrm{kcal} / \mathrm{mol}$ more stable than the bird, has, however, one imaginary frequency. Following the vector indicated by the vibration, we are led to the still more stable 5 -iodocyclopenta-1,3-diene, ${ }^{14} 10$, which is no less than $73 \mathrm{kcal} / \mathrm{mol}$ lower in energy than the bird structure (4). Given that the birds are computed to be local minima, and the bicyclic structures are not, we wondered what kind of barrier protects the bird structures from highly exothermic decomposition to the classical substituted cyclopentadienes.

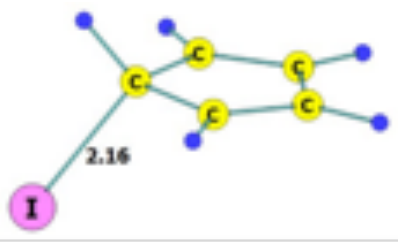

10

The mechanism of isomerization was explored by a potential energy surface scan and is summarized in Fig. 1 . The reaction $4 \rightarrow 10$ has a barrier of $14 \mathrm{kcal} / \mathrm{mol}$, 
through transition state 11 , which retains the $C_{s}$ symmetry of the bird. The path to product continues with a mirror plane of symmetry maintained until effectively a bicyclic structure (7) is reached, at which point the reaction bifurcates along two enantiomeric paths leading to a cyclopentadienyl iodide structure (10). Such "twostep-no-intermediate" mechanisms are known for a number of potential energy surfaces. ${ }^{15}$ Structure 7 may also be viewed as the already studied 1, 2-halogenmigration transition state of cyclopentadienyl halides. ${ }^{16-17}$ The activation barrier for 1,2-iodine migration calculated for 10 in ref. $17(\approx 20 \mathrm{kcal} / \mathrm{mol})$ at $M P 2 / 6-31+\mathrm{g}(\mathrm{d})$ is close to that calculated by us $(19 \mathrm{kcal} / \mathrm{mol})$. The geometries are also close to each other.

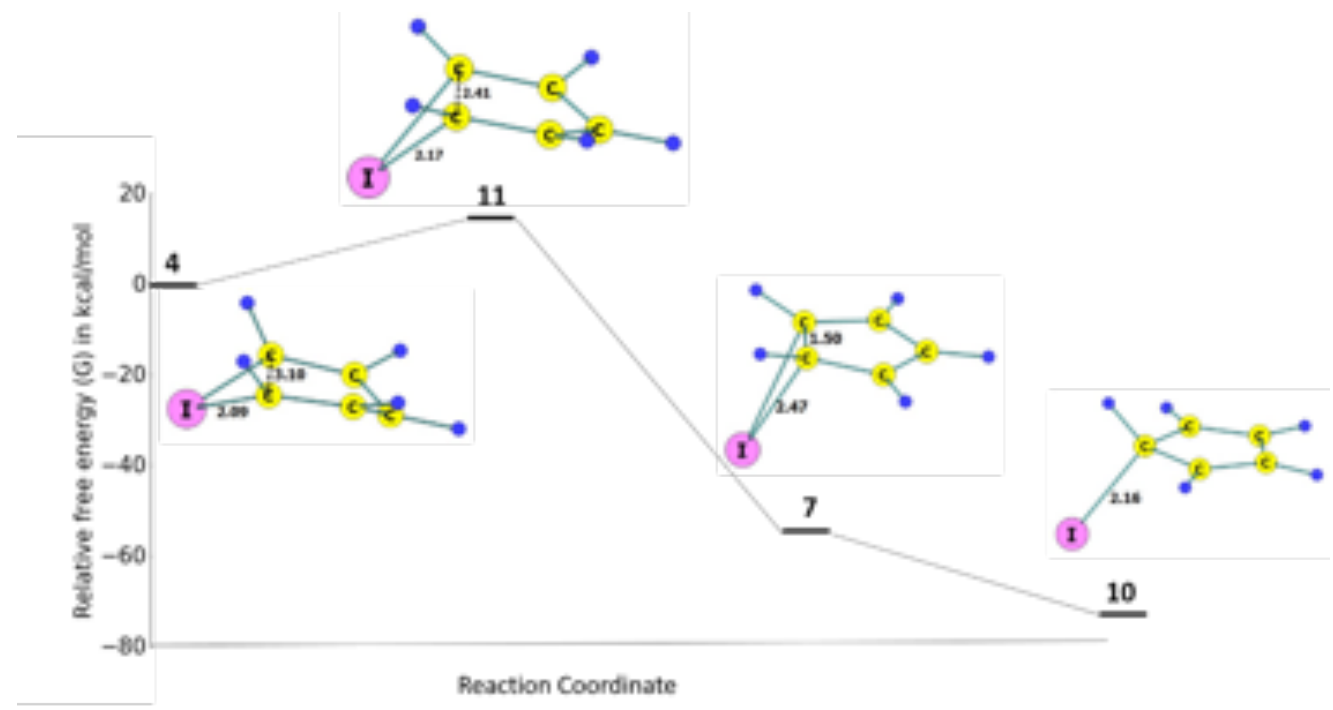

Figure 1. Mechanism of isomerization of iodabenzene.

The relative energies of the bird and cyclopentadienyl structures of ioda-, broma-, chlora- and fluorabenzenes and the barrier for bird to cyclopentadienyl isomerization are shown in Table 1, as are the natural charges on the halogen atom in 
the bird structures. The higher relative energy and low activation barrier of fluorabenzene is consistent with the zwitterionic nature of the molecule.

Table 1. Comparison of iodabenzene to the $\mathrm{Br}, \mathrm{Cl}$, and $\mathrm{F}$ analogs.

\begin{tabular}{|c|c|c|c|}
\hline $\begin{array}{l}X \quad \text { in } \\
\mathrm{C}_{5} \mathrm{H}_{5} \mathrm{X}\end{array}$ & $\begin{array}{l}\text { Energy of the bird } \\
\text { structure relative to the } \\
5 \text {-halo-cyclopentadiene, } \\
\text { in } \mathrm{kcal} / \mathrm{mol}\end{array}$ & $\begin{array}{l}\text { Barrier }\left(\Delta G^{\#}\right) \text { for the } \\
\text { isomerization from bird to } \\
5 \text {-halocyclopentadiene } \\
(\mathrm{kcal} / \mathrm{mol})\end{array}$ & $\begin{array}{l}\text { Charge on } \mathrm{X} \text { in } \\
\text { t h e b i d } \\
\text { structure }\end{array}$ \\
\hline I & 73 & 14 & 0.75 \\
\hline $\mathrm{Br}$ & 73 & 13 & 0.59 \\
\hline $\mathrm{Cl}$ & 72 & 13 & 0.49 \\
\hline $\mathrm{F}$ & 92 & 2 & -0.18 \\
\hline
\end{tabular}

Of course, the 5-iodocyclopentadiene structure (10) does not exhaust the isomeric possibilities for stoichiometry $\mathrm{C}_{5} \mathrm{H}_{5} \mathrm{l}$. 1- and 2-iodocyclopentadiene structures 12 and 13 come to mind, as do the isomers of $14-16$ and still other constitutional isomers. We have not explored in detail the variety of available Lewis structures, as we wanted to remain close to the monocyclic form. However, all the iodocyclopentadiene isomers are close to each other in energy, while 14-16 lie 30-40 $\mathrm{kcal} / \mathrm{mol}$ higher. 


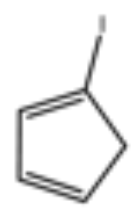

12

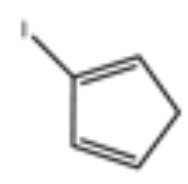

13

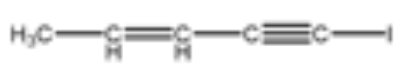

14

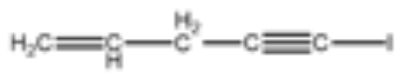

16

15

We note that Glukhovtsev, Laiter and Simkin, in a study of halogenacyclobutadienes, $(\mathrm{CH})_{3} \mathrm{X}$ (now with an aromatic $\pi$-electron system) also found that classical isomers were much stabilized. ${ }^{18}$

An $\mathrm{SF}_{3}$ Analogue. There is an intriguing study by Xie, Schaefer, and Thrasher of an $\mathrm{SF}_{3}$ analogue of the iodabenzene. ${ }^{19}$ The equilibrium structure they obtained is shown in 17.

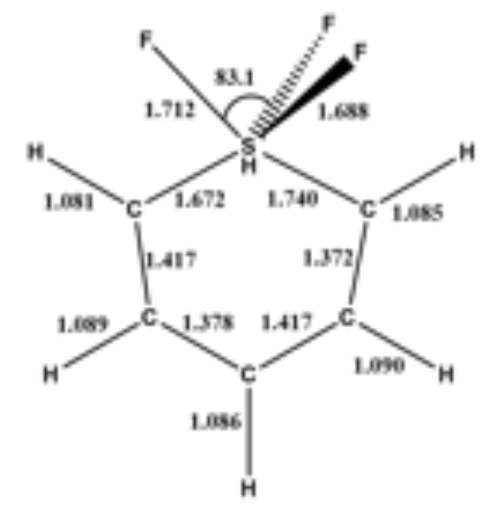

17

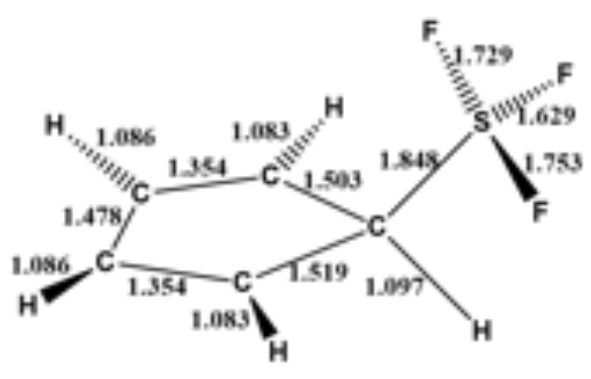

18

Seeing a resemblance between the flat iodabenzene ring geometry and 17 , we told our story to H. F. Schaefer. Y. Xie then proceeded to study structural alternatives analogous to our bicyclic (7) and cyclopentadienyl (10) isomers. The Georgia group indeed located these, ${ }^{20}$ approximately 5 and $37 \mathrm{kcal} / \mathrm{mol}$ more stable than 17 . We 
show the lowest energy structure they obtained, 18. It may be seen as an $\mathrm{SF}_{3^{-}}$ substituted cyclopentadiene, or alternatively as a hypervalent $\mathrm{SF}_{4}$ with one $\mathrm{F}$ substituted by a cyclopentadienyl group.

An Analogy Between lodabenzene and a Meisenheimer Complex. The pentadienyl anion moiety in 6 immediately calls up an analogy to the known Meisenheimer complexes 19. ${ }^{21,22}$ Optimization of the parent structure of these, $\mathrm{C}_{6} \mathrm{H}_{7}^{-}$(19), gave structure 20 , which indeed shows a remarkable geometrical similarity to the bird iodabenzene (4). The charge distribution of 20 , shown in 21 , indicates that the ortho and para positions are more negatively charged than the meta position, similar to iodabenzene bird.

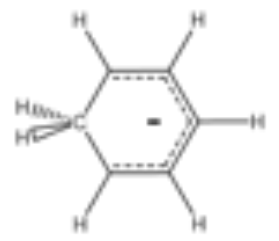

19

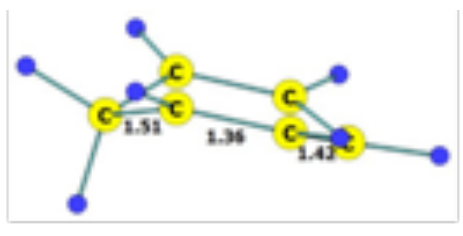

20

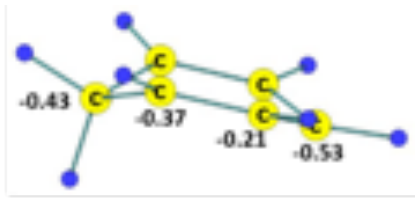

21

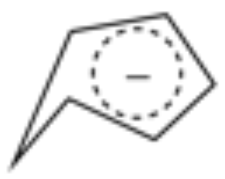

22 
Recent computational studies on $\mathrm{C}_{6} \mathrm{H}_{7}{ }^{-}$also find the bird-like geometry. ${ }^{23}$ Earlier theoretical investigations by Olah and Haddon report a planar $\mathrm{C}_{2 v}$ structure for $\mathrm{C}_{6} \mathrm{H}_{7}$ at the MINDO/3 level. ${ }^{24,25}$ Haddon also located a second local minimum at higher energy, corresponding to what he called a homocyclopentadienide ion, 22 . This is like the bicyclic geometry that we explored above for iodabenzene. Homoconjugation was very much in the air at the time, and $\mathrm{C}_{6} \mathrm{H}_{7}{ }^{-}$was the subject of some discussion and good experiment. $26,27,28$

How to stabilize iodabenzene? We are not deferred by the $73 \mathrm{kcal} / \mathrm{mol}$ instability of the bird form. The similarity in geometry, electronic structure and charge distribution immediately suggests a strategy of stabilizing the iodabenzene structure, analogous to that used in the Meisenheimer complexes: Put $\pi$-acceptors in the ortho and para positions. ${ }^{28}$ We examined iodabenzene, substituted in ortho and para positions with nitro groups (23), where the negative charge accumulates. Similar to the trinitrosubstituted Meisenheimer complex (24), trinitro-iodabenzene (23) is calculated as planar. We also examined the corresponding $\mathrm{Br}, \mathrm{Cl}$ and $\mathrm{F}$ analogs. While trinitrobromabenzene is computed as a planar minimum, the $\mathrm{Cl}$ and $\mathrm{F}$ analogs are calculated as minima with bird structure.

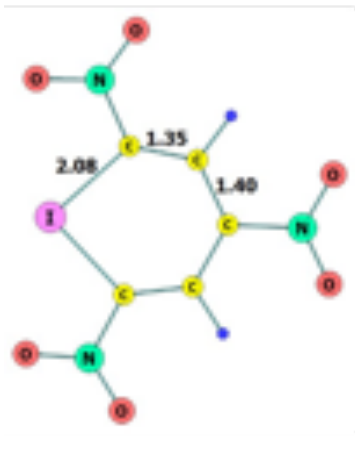

23

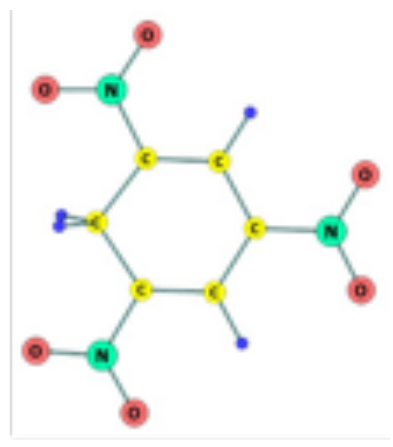

24 
Table 2. Effect of $\pi$-accepting substituents on the stability of halogenabenzenes. The natural charge on halogen atom is also shown. The zero of energy is the 5cyclopentadienyl halide in each case.

\begin{tabular}{|c|c|c|c|c|c|}
\hline \multirow{2}{*}{$\begin{array}{l}\mathrm{H} \text { a log e } \mathrm{n} \text { in } \\
\text { halogenabenzen } \\
\mathrm{e}\end{array}$} & \multirow{2}{*}{$\begin{array}{l}\text { Substituent } \\
\text { (ortho, para- } \\
\text { trisubstitutio } \\
\text { n) }\end{array}$} & \multicolumn{2}{|c|}{$\begin{array}{l}\text { Relative energy } \\
\text { in } \mathrm{kcal} / \mathrm{mol}\end{array}$} & \multirow{2}{*}{$\begin{array}{l}\text { Barrier for the } \\
\text { isomerization } \\
\text { from bird or } \\
\text { planar to } \\
\text { cyclopentadienyl } \\
\text { (kcal/mol). }\end{array}$} & \multirow{2}{*}{$\begin{array}{l}\text { Charge on } \\
x \text { in the } \\
\text { bird or } \\
\text { p l a n a r } \\
\text { structure }\end{array}$} \\
\hline & & bird & planar & & \\
\hline \multirow[t]{2}{*}{ I } & $-\mathrm{NO}_{2}$ & $\cdots$ & 40 & 30 & 1.06 \\
\hline & $-\mathrm{CN}$ & 55 & ---- & 18 & 0.90 \\
\hline \multirow[t]{2}{*}{$\mathrm{Br}$} & $-\mathrm{NO}_{2}$ & $-\cdots$ & 49 & 23 & 0.79 \\
\hline & $-\mathrm{CN}$ & 57 & --- & 16 & 0.70 \\
\hline \multirow[t]{2}{*}{$\mathrm{Cl}$} & $-\mathrm{NO}_{2}$ & 54 & -..- & 19 & 0.63 \\
\hline & $-\mathrm{CN}$ & 57 & --.- & 16 & 0.58 \\
\hline \multirow[t]{2}{*}{$F$} & $-\mathrm{NO}_{2}$ & 83 & $-\cdots$ & 6 & -0.11 \\
\hline & $-\mathrm{CN}$ & 78 & $\ldots$ & 7 & -0.14 \\
\hline
\end{tabular}

We also tried some structures with $-\mathrm{CN}$ groups as substituents in ortho and para positions; these are also local minima with the bird structure for all halogens. Table 2 lists the energy values of the nitro- and cyano- substituted halogenabenzenes relative to the 5-cyclopentadienyl structure, and the barrier for their isomerization. Note the general stabilization of the planar or bird compounds by $10-30 \mathrm{kcal} / \mathrm{mol}$ (relative to the unsubstituted case) on trinitro or tricyano substitutions. At the same time, the barrier for the isomerization from the halogenabenzene to cyclopentadienyl increases 
with substitution by $\pi$-accepting groups. The increase in the positive charge on halogen accompanying $\pi$-accepting substitution is also evident from a comparison of Table 1 and 2. Planarization can be achieved even with a single $\mathrm{NO}_{2}$ substituent, provided it is in the ortho position where the negative charge is maximum. We think the trinitro and tricyano bird halogenabenzenes (not F) may be isolable compounds at low temperatures.

Another strategy to remove two electrons from the $\pi$-system of iodabenzene comes to mind. Imagine the following sequence of hypothetical reactions: (a) Remove the ortho hydrogens from iodabenzene. That leaves a diradical 25a. (b) Take the two "extra" electrons from the eight-electron $\pi$-system of $25 \mathrm{a}$, and put them into the $\sigma$ system, 25b. (c) Add two boranes, $\mathrm{BH}_{3}$, to stabilize the new $\sigma$-electron pairs, reaching a zwitterionic valence structure $25 c$.

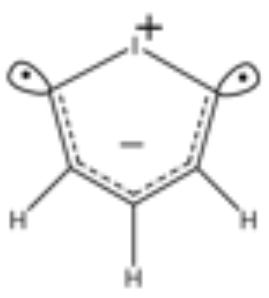

$25 a$

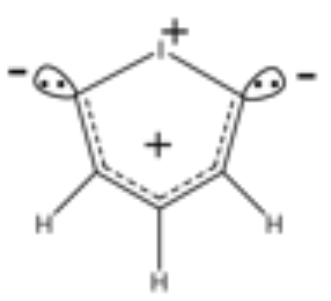

$25 b$

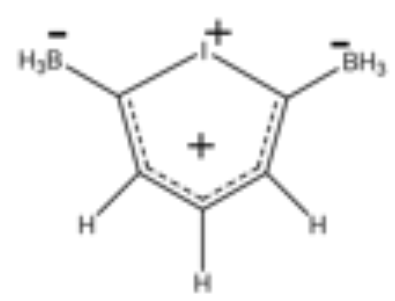

$25 \mathrm{c}$

Structure $25 c$ was computed to be a planar $6 \pi$-electron aromatic system (26). Replacement of $\mathrm{BH}_{3}$ with isolobal transition metal fragments should also be feasible. Once again, the less likely $F$ analog is not a minimum. The natural charge on iodine in 26 is 0.96 compared to 0.75 in 4 . 


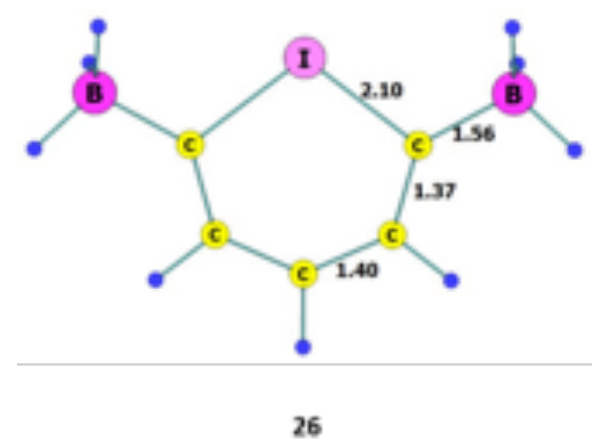

A triplet state for the bird. The bird structure 4, attractive as it is, is of high energy and the HOMO-LUMO gap is $5.5 \mathrm{eV}$. For high energy singlet structures, one needs to think about the possibility of low lying triplet states. We indeed found a triplet state, 27 , which is only $4 \mathrm{kcal} / \mathrm{mol}$ higher in energy. This is an unrestricted $\mathrm{M} 06-2 \mathrm{X}$ result, and we were worried if this method was adequate for estimating the singlet-triplet splitting. So, we also carried out GMC-QDPT calculations ${ }^{29,30}$ with an active space of 10 orbitals and 12 electrons and obtained results qualitatively consistent. The triplet state is $5.5 \mathrm{kcal} / \mathrm{mol}$ higher in energy than the singlet at GMC-QDPT level. In the triplet state, one unpaired electron occupies the $\pi^{*}$ level and the other enter a C-I antibonding $\sigma^{*}$ level. A symmetry lowering induced by what could be viewed as a pseudo-Jahn-Teller effect concentrates the C-I antibonding interaction on one side, resulting in an elongated I-C bond. An unsymmetric distortion ensues.

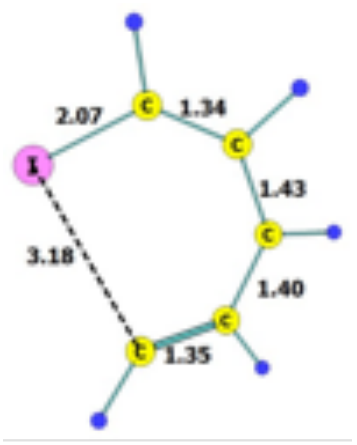


Structure and bonding. The bird structure of iodabenzene is related to the boat structure of benzene dianion, $\mathrm{C}_{6} \mathrm{H}_{6}{ }^{2-} \cdot{ }^{31-32}$ The two excess electrons in $\mathrm{C}_{6} \mathrm{H}_{6}{ }^{2-}$ occupy LUMO1 of benzene (Fig. 2) and the structure would be expected to pucker to decrease the antibonding interaction between neighboring atoms and also (perhaps) to turn on a cross-ring overlap, as shown by the dotted line. Indeed, normally the puckered structure is preferred to the planar one, unless the out-of-plane distortion is sterically prevented. ${ }^{37}$ Examples of both puckered and undistorted structures are known in literature, where the $\mathrm{H}$ of $\mathrm{C}_{6} \mathrm{H}_{6}{ }^{2-}$ are replaced by silyl groups. ${ }^{37}$

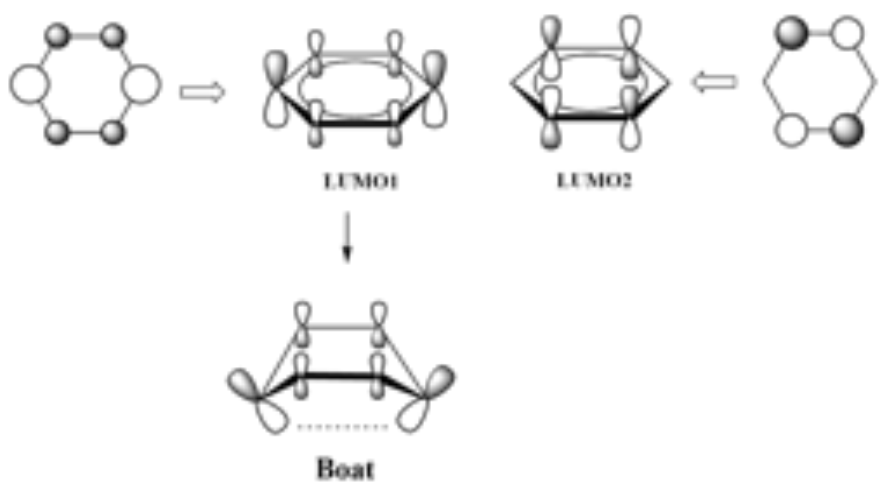

Figure 2. LUMOs of benzene and the transformation of LUMO1 in the boat structure

We think that the reason for puckering of iodabenzene is similar. The HOMO in planar and bird structures is shown in two views in Fig. 3. Notice how the puckering helps in decreasing the antibonding interaction between I and $\mathrm{C}$ in the HOMO. The $\mathrm{HOMO}$ of $(\mathrm{CH})_{5}$ l gets stabilized by $0.7 \mathrm{eV}$ on puckering. 

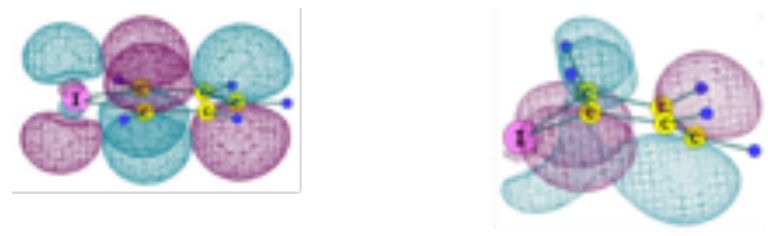

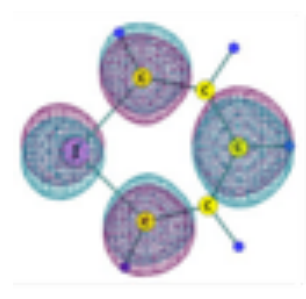

Planar

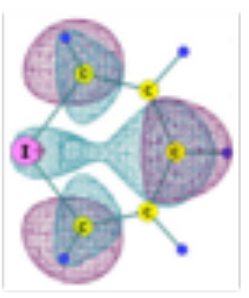

Bird

Figure 3. HOMO of iodabenzene planar and bird structures, shown in two views.

The analogy we found between the Meisenheimer complex and bird iodabenzene has limitations. So the cyclopentadienyl structure of the Meisenheimer complex (28) is less stable than the bird structure $(20)$ by $35 \mathrm{kcal} / \mathrm{mol}$. This is understandable, as structure 28 leads to localization of negative charge on the primary carbon atom.

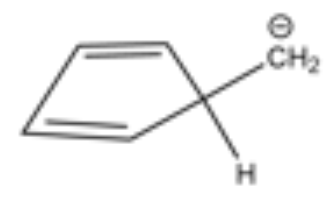

28

\section{CONCLUSION}

lodabenzene, formally an antiaromatic $8 \pi$-electron system, acquires stability by an out-of-plane puckering, which decreases the antibonding interaction in the HOMO. The resulting bird structure is similar in charge distribution and geometry to the wellknown Meisenheimer complex. The resemblance leads to the same strategy as one would use to stabilize the Meisenheimer complex for iodabenzene, i.e., to put $\pi-$ 
accepting substituents in the ortho and para positions, where the negative charge accumulates. Way downhill in energy, a classically bonded iodocyclopentadiene structure awaits $(\mathrm{CH})_{5} \mathrm{l}$. While the barrier for the isomerization from iodabenzene bird to the cyclopentadienyl structure is calculated as only $14 \mathrm{kcal} / \mathrm{mol}$, that for the trinitro-substituted one is $30 \mathrm{kcal} / \mathrm{mol}$. This makes us optimistic about the experimental realization of the bird iodabenzene isomer.

\section{ASSOCIATED CONTENT}

\section{Supporting Information}

Coordinates and energies of the computed structures.

\section{AUTHOR INFORMATION}

Corresponding Authors

*rawash@yu.edu.jo

*rh34@cornell.edu

ORCID

Roald Hoffmann: 0000-0001-5369-6046

\section{Author Contributions}

AMR designed, carried out and interpreted research, wrote paper; PCP designed, carried out and interpreted research, wrote paper; TZ contributed calculations and methodology; RH designed and interpreted research, wrote paper.

\section{Notes}

The authors declare no competing financial interest. 


\section{ACKNOWLEDGEMENTS}

We are grateful to the National Science Foundation for its support of this work through research grant CHE-1305872. We are grateful to Paul Kiprof and Viktor Zhdankin from the U. of Minnesota Duluth, and to H. F. Schaefer, III, for useful discussions. 


\section{REFERENCES}

${ }^{1}$ Zhdankin, V. V. Hypervalent Iodine Chemistry: Preparation, Structure, and Synthetic Applications of Polyvalent Iodine Compounds, Wiley, 2013.

${ }^{2}$ Akiba, K. Chemistry of Hypervalent Compounds. 1998, New York: Wiley VCH.

${ }^{3}$ Zhdankin, V. V.; Stang, P. J., Chem. Rev., 2008, 108, 5299-5358.

${ }^{4}$ Glukhovtsev, M. N. Russ. J. Org. Chem. 1991, 27 (2), 363.

${ }^{5}$ Frisch, M. J.; Trucks, G. W.; Schlegel, H. B.; Scuseria, G. E.; Robb, M. A.; Cheeseman, J. R.;

Scalmani, G.; Barone, V.; Mennucci, B.; Petersson, G. A.; Nakatsuji, H.; Caricato, M.; Li, X.;

Hratchian, H. P.; Izmaylov, A. F.; Bloino, J.; Zheng, G.; Sonnenberg, J. L.; Hada, M.; Ehara, M.;

Toyota, K.; Fukuda, R.; Hasegawa, J.; Ishida, M.; Nakajima, T.; Honda, Y.; Kitao, O.; Nakai, H.;

Vreven, T.; Montgomery, J. A., Jr.; Peralta, J. E.; Ogliaro, F.; Bearpark, M.; Heyd, J. J.; Brothers,

E.; Kudin, K. N.; Staroverov, V. N.; Kobayashi, R.; Normand, J.; Raghavachari, K.; Rendell, A.;

Burant, J. C.; Iyengar, S. S.; Tomasi, J.; Cossi, M.; Rega, N.; Millam, J. M.; Klene, M.; Knox, J.

E.; Cross, J. B.; Bakken, V.; Adamo, C.; Jaramillo, J.; Gomperts, R.; Stratmann, R. E.; Yazyev,

O.; Austin, A. J.; Cammi, R.; Pomelli, C.; Ochterski, J. W.; Martin, R. L.; Morokuma, K.;

Zakrzewski, V. G.; Voth, G. A.; Salvador, P.; Dannenberg, J. J.; Dapprich, S.; Daniels, A. D.;

Farkas, Ö.; Foresman, J. B.; Ortiz, J. V.; Cioslowski, J.; Fox, D. J. Gaussian 09, Revision D.01;

Gaussian, Inc.: Wallingford, CT, 2009.

${ }^{6}$ Zhao, Y.; Truhlar, D. G. Theor. Chem. Acc. 2008, 120, 215.

${ }^{7}$ Weigend, F.; Ahlrichs, R. Phys. Chem. Chem. Phys. 2005, 7, 3297. 
${ }^{8}$ Roos, B. O.; AdV. Chem. Phys. 1987, 69, 399.

${ }^{9}$ Schmidt, M. W.; Baldridge, K. K.; Boatz, J. A.; Elbert, S. T.; Gordon, M. S.; Jensen, J. H.;

Koseki, S.; Matsunaga, N.; Nguyen, K. A.; Su, S. J.; Windus, T. L.; Dupuis, M.; Montgomery, J. A.; J. Comput. Chem. 1993, 14, 1347.

10 Zhao, Y.; and Truhlar, D. G. Acc. Chem. Res. 2008, 41 (2), 157.

${ }^{11}$ Glendening, E. D.; Reed, A. E.; Carpenter, J. E.; Weinhold, F. QCPE Bull. 1990, 10, 58.

${ }^{12}$ See, for instance, Stang, P. J. Angew. Chem. Int. Ed. Engl. 1992, 31, 274; Stang, P.J. Acc.

Chem. Res. 1991, 24, 304, Also Boldyrev, A. I.; Zhdankin, V. V.; Simons, J.; Stang, P. J. J. Am.

Chem. Soc. 1992, 114, 10569. Also, in the context of iodine making a choice between hypervalent and normal bonding: Ivanov, A. S.; Popov, I. A.; Boldyrev, A. I.; Zhdankin, V. V. Angew. Chem. Int. Ed. 2014, 53, 9617.

${ }^{13}$ Hoffmann, R.; Woodward, R. B. Acc. Chem. Res. 1968, l(1), 17.

${ }^{14}$ Breslow, R.; Hoffman Jr, J. M. J. Am. Chem. Soc. 1972, 94 (6), 2110.

${ }^{15}$ Ess, D. H.; Wheeler, S. E.; Iafe, R. G.; Xu, L.; Çelebi-Ölçüm, N.; Houk, K. N. Angew. Chem. Int. Ed. 2008, 47, 7592.

${ }^{16}$ Pye, C. C.; Poirier, R. A. Can. J. Chem. 2005, 83(9), 1299.

17 Breslow, R.; Canary, J. W. J. Am. Chem. Soc. 1991, 113 (10), 3950.

${ }^{18}$ Glukhovtsev, M. N.; Laikin, S. Y.; Simkin, B. Y. Zh. Org. Khim. 1992, 28, 1789; Russian J.

Org. Chem. 1992, $28(9), 1431$.

${ }^{19}$ Xie, Y.; Schaefer, H. F., III; Thrasher, J. S. J. Mol. Struct (Theochem). 1961, 234, 247.

${ }^{20}$ Xie, Y.; Schaefer, H. F., III private communication, 1/11/10.

${ }^{21}$ Meisenheimer, J. Justus Liebigs Annalen der Chemie 1902, 323 (2), 205.

${ }^{22}$ Artamkina, G. A.; Egorov, M. P.; Beletskaya, I. P. Chem. Rev. 1982, 82 (4), 427. 
${ }^{23}$ Coletti, C.; Re, N. Chem. Phys. 2012, 398, 168.

${ }^{24}$ Olah, G. A.; Asensio, G.; Mayr, H.; Schleyer, P. v. R. J. Am. Chem. Soc. 1978, 100 (14), 4347.

${ }^{25}$ Haddon, R. C. J. Org. Chem. 1979, 44 (21), 3608.

${ }^{26}$ Lee, R. E.; Squires, R. R. J. Am. Chem. Soc. 1986, 108 (17), 5078.

${ }^{27}$ Kleinpeter, E.; Koch, A. Tetrahedron 2009, 65, 5350.

${ }^{28}$ Gluz, E.B.; Glukhovtsev, M. N.; Simkin, B. Ya.; Minkin, V. I. Russian J. Organic Chem. 1992, 28 (9), 1439; Zhur. Org. Khim. 1992, $28(9), 1798$.

${ }^{29}$ Ebisuzaki, R.; Watanabe, Y.; Nakano, H. Chem. Phys. Lett. 2007, 442, 164.

${ }^{30}$ Nakano, H.; Uchiyama, R.; Hirao, K. J. Comput. Chem. 2002, 23, 1166.

31 Sakurai, H. Pure \& Appl. Chem. 1994, 66 (7), 1431.

32 Podlogar, B. L.; Glauser, W. A.; Rodriguez, W. R.; Raber, D. J. J. Org. Chem. 1988, 53 (9), 2127. 


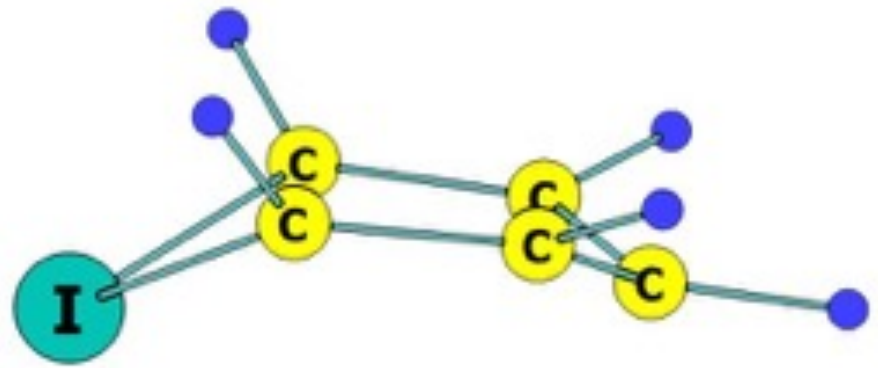

